\title{
Response of macrobenthic communities to changes in water quality in a subtropical, microtidal estuary (Oso Bay, Texas)
}

\author{
Kevin de Santiago ${ }^{1}$, Terence A. Palmer ${ }^{2}$ (D), Michael S. Wetz ${ }^{1,2}$ and Jennifer Beseres Pollack ${ }^{1,2, *}$ (D) \\ ${ }^{1}$ Life Sciences Department, Texas A\&M University - Corpus Christi, 6300 Ocean Drive, Unit 5869, Corpus Christi, TX78412- \\ 5869, USA, and ${ }^{2}$ Harte Research Institute for Gulf of Mexico Studies, Texas A\&M University - Corpus Christi, 6300 Ocean \\ Drive, Unit 5869, Corpus Christi, TX78412-5869, USA \\ *Corresponding author. Email address: jennifer.pollack@tamucc.edu
}

(Received 30 June 2020; Accepted 04 August 2020)

\begin{abstract}
The influence of nutrient loading and other anthropogenic stressors is thought to be greater in low inflow, microtidal estuaries, where there is limited water exchange. This 11-month study compared spatial changes in macrofaunal communities adjacent to regions that varied in land cover in Oso Bay, Texas, an estuarine secondary bay with inflow dominated by hypersaline discharge, in addition to discharge from multiple municipal wastewater treatment plants. Macrofauna communities changed in composition with distance away from a wastewater treatment plant in Oso Bay, with the western region of the bay containing different communities than the head and the inlet of the bay. Ostracods were numerically dominant close to the wastewater discharge point. Macrobenthic community composition is most highly correlated with silicate concentrations in the water column. Silicate is negatively correlated with salinity and dissolved oxygen, and positively correlated with nutrients within the bay. Results are relevant for environmental management purposes by demonstrating that point-source discharges can still have ecological effects in hydrologically altered estuaries.
\end{abstract}

Keywords: Nutrient enrichment; silicate; anthropogenic; ecological indicator; wastewater; ostracoda

\section{Introduction}

Coastal systems are increasingly subject to environmental degradation due to stressors of both natural and anthropogenic origin. One stressor, nutrient loading, contributes to algal blooms and subsequent decomposition that can limit dissolved oxygen in the water column (Pinckney et al., 2001). Macrobenthos are particularly sensitive to organic enrichment, making these communities useful for studying the influence of nutrient inputs on a system (Pearson \& Rosenberg, 1978). Oso Bay, Texas, USA, is a shallow (mean $1 \mathrm{~m}$ ), estuarine secondary bay in the northwestern Gulf of Mexico (Figure 1) experiencing rapid urbanization coincident with increased nutrient and organic matter inputs (Wang et al., 2018; Wetz et al., 2016). Microtidal, low-flow estuaries such as Oso Bay are believed to be more sensitive to anthropogenic influences than "classical" estuaries with strong riverine and/or tidal influences due to limited flushing (Bricker et al., 2007). This sensitivity makes management of these systems more challenging.

\footnotetext{
(c) The Author(s), 2020. Published by Cambridge University Press. This is an Open Access article, distributed under the terms of the Creative Commons Attribution licence (http://creativecommons.org/licenses/by/4.0/), which permits unrestricted re-use, distribution, and reproduction in any medium, provided the original work is properly cited.
} 


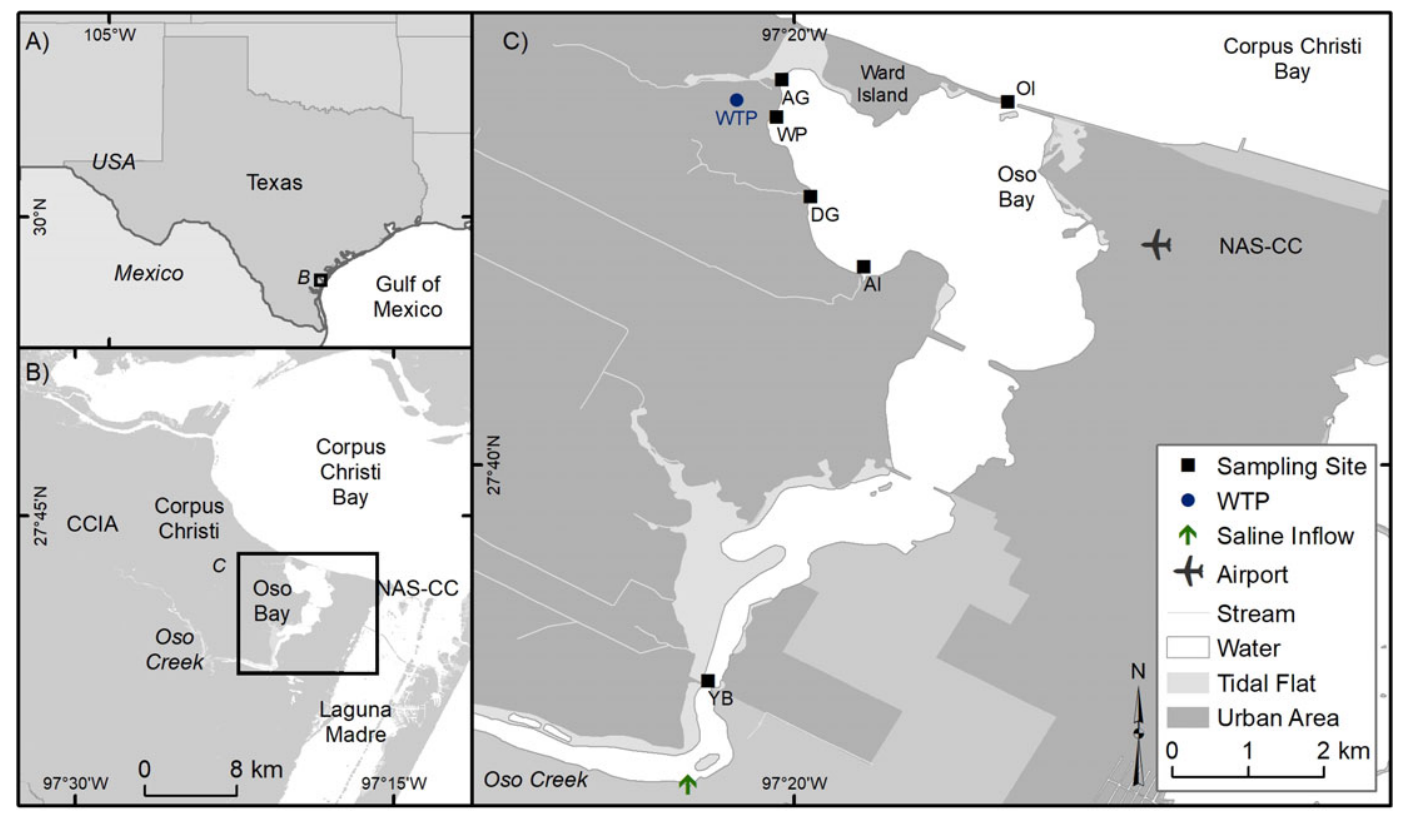

Figure 1. Sampling sites within Oso Bay. WTP = Wastewater treatment plant.

\section{Objective}

The aim of this 11-month study was to analyze spatial changes in estuarine macrobenthic communities adjacent to regions that varied in land cover. Oso Bay has multiple stressors, including its primary tributary, Oso Creek, being dominated by discharge of hypersaline cooling water from a power plant as well as discharge from multiple municipal wastewater treatment plants, while another wastewater treatment plant discharges directly into Oso Bay. This study focuses on spatial differences in land cover and the influence of nutrient inputs on macrobenthic communities to inform ongoing management activities by state (Texas Commission on Environmental Quality) and federal (U.S. Environmental Protection Agency) environmental management agencies.

\section{Methods}

Macrobenthic infaunal communities and sediment chlorophyll concentrations were collected using core samples monthly from February 2013 to January 2014 (de Santiago et al., 2020). Sediment grain size was sampled in January 2014. Water quality measurements (salinity, temperature, dissolved oxygen, $\mathrm{pH}$ ) and water chemistry samples $\left(\mathrm{SiO}_{4}{ }^{2-}, \mathrm{NH}_{4}{ }^{+} ; \mathrm{NO}_{2}+\mathrm{NO}_{3}, \mathrm{PO}_{4}{ }^{3-}\right.$, dissolved organic carbon [DOC], dissolved organic nitrogen $[\mathrm{DON}]$, total dissolved nitrogen [TDN]) were taken three to five days prior to benthic sampling (Wetz et al., 2016).

Sampling occurred at six sites within Oso Bay, including the head of Oso Bay below a hypersaline discharge point to Oso Creek (Yorktown Bridge, YB), and the mouth at Oso Bay inlet (OI), as well as four sites in the western region of the bay: an active golf course that uses reclaimed wastewater from for watering (AG), a defunct golf course (DG), a mix of agricultural land and impervious surface (AI), and a mixed residential area with outflow dominated by effluent from a municipal wastewater treatment plant (WP) (Figure 1). Multivariate statistical techniques (non-metric multidimensional scaling (nMDS), principal component analysis (PCA), Bio-Env; Clarke \& Ainsworth, 1993) and Pearson's correlations were used to characterize macrobenthic community composition and water quality. 


\section{Results}

Macrobenthic communities are clustered into two groups: the four sites in the western region of the bay, and the stations at the inlet and head of the bay (Figure 2, Figure S1). The four sites in the western region were characterized by having high abundances of ostracods and oligochaetes but low abundances of bivalves and the polychaetes Mediomastus californiensis, Brania sp. and Scoloplos sp. (Suppl. Table 1). Mean ostracod abundance at WP was $\geq 50$ times greater than at any other site.

Nutrient concentrations decreased and salinity increased with distance away from WP (Figure 3). Spatial variations in macrofaunal community structure are most highly correlated with silicate concentrations $(r=0.428, p=0.001)$, followed by the combination of silicate, DOC and salinity $(r=0.407$, $\mathrm{p}=0.001$; Bio-Env). Mean silicate concentrations were 2-11X higher at WP, AG and DG than AI, OI and YB (Figure S2, Table S2). Silicate is negatively correlated with salinity and dissolved oxygen and positively correlated with nutrients $\left(\mathrm{NH}_{4}{ }^{+} ; \mathrm{NO}_{2}+\mathrm{NO}_{3}, \mathrm{PO}_{4}{ }^{3-}\right.$, DOC, DON, TDN; Table S3).

\section{Discussion}

Oso Bay has experienced rapid urbanization in recent decades coincident with shifts in water quality and symptoms of eutrophication (Bugica et al., 2020). Macrobenthos community composition corroborates with previous water quality results indicating impairment of the western region of the bay due to the effluent-based nutrient inputs at WP (Wang et al., 2018; Wetz et al., 2016). The macrobenthic community in the nutrient-rich western region of the bay was dominated by ostracods, known indicators of reduced water quality and sewage discharge (Rosenfeld \& Ortal, 1983), and oligochaetes, commonly used as indicators of organic pollution (McLusky et al., 1980). Wastewater discharge can also be a significant source of silicate (Clark et al., 1992; Van Dokkum et al., 2004), which was highest in the western region of the bay and most strongly influenced macrobenthic community composition over space and time. Although the OI and YB sites are most separated in space, upstream hypersaline discharge appears to facilitate a macrobenthic community at YB that is similar to OI.

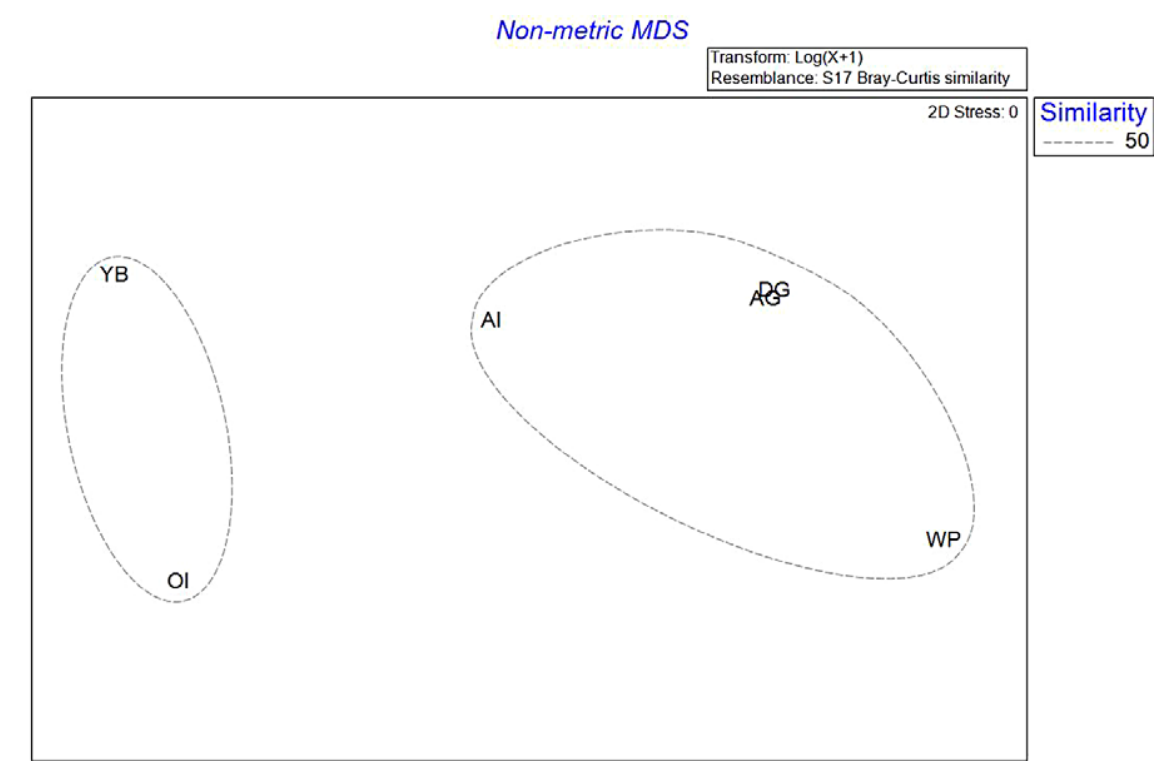

Figure 2. Non-metric multidimensional scaling plot of mean community composition at each station. 

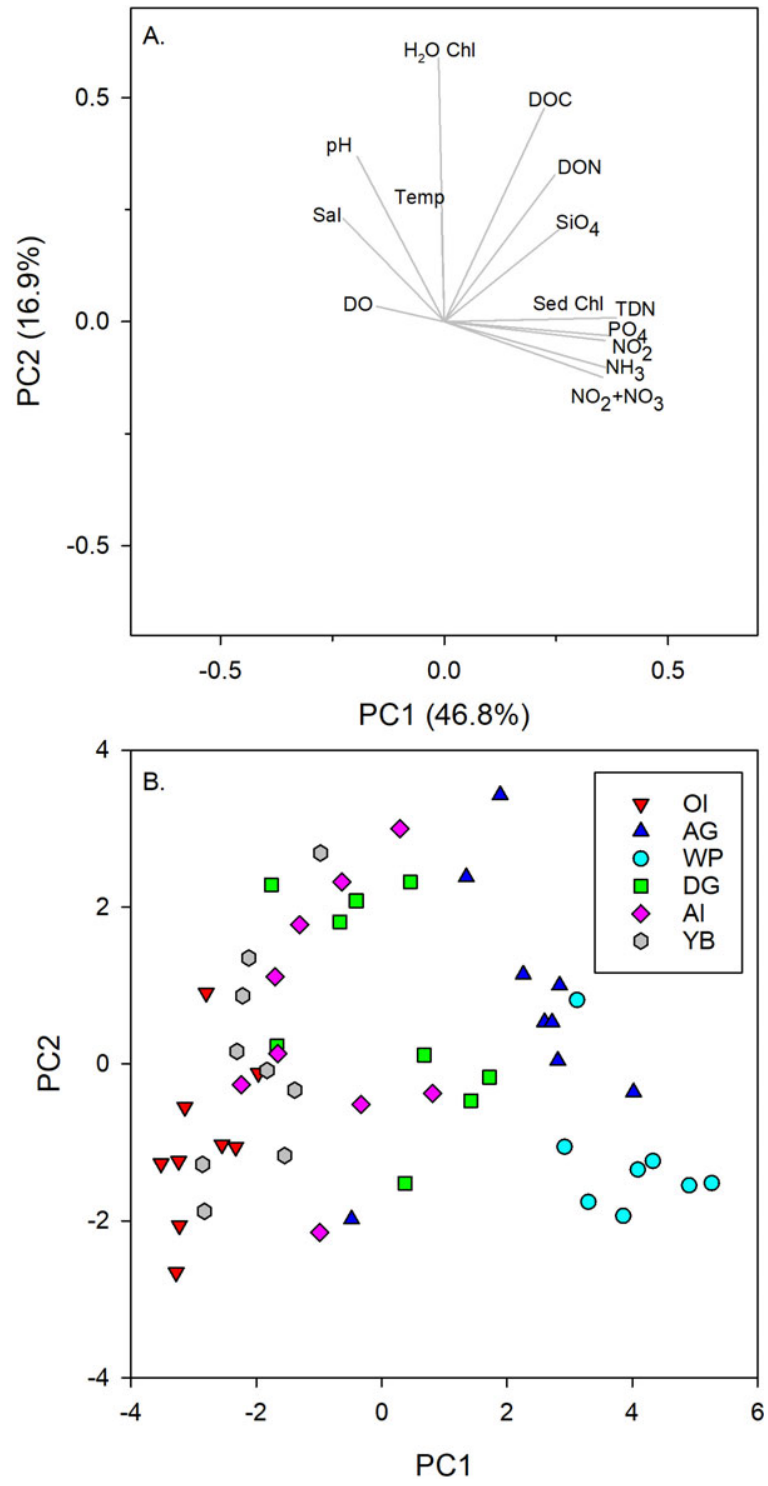

Figure 3. Principal components analysis of spatial variation in water quality and sediment chlorophyll. Variable vectors (top) and loading scores (bottom).

\section{Conclusion}

The dominant point source of nutrients and fresh water in the western region of Oso Bay (wastewater treatment plant) influences macrofaunal communities. Despite nutrient concentrations decreasing away from WP, macrobenthic communities remain more similar than those occurring at the head and inlet of the bay, likely due to relatively lower rates of water exchange in the western region. This correlation between macrofauna and water quality in Oso Bay indicates that macrobenthic communities are influenced by nutrient loading in shallow, microtidal estuaries, and can successfully be used as ecological indicators. The data that support the findings of this study are openly available in GRIIDC (de Santiago et al., 2020). 
Acknowledgements. The authors thank two anonymous reviewers for constructive comments that improved the quality of this manuscript. We also thank Ken Hayes, Kelsey Fisher, Lynn Price and several others for collecting and analyzing water quality samples and Alex Nunez for management insights. We are grateful to Diana Sokoly for assistance with Oso Bay field sampling. Lastly, we thank the Gulf of Mexico Research Initiative Information and Data Cooperative for storing, and allowing open access of, the data that were generated in this study (de Santiago et al., 2020).

Author Contributions. JBP, KDS, and MSW conceived and designed the study. KDS and MSW conducted data collection. KDS and TAP performed statistical analyses. TAP and JBP wrote the article.

Funding Information. This project was funded in part by a grant approved by the Texas Land Commissioner pursuant to National Ocean and Atmospheric Administration (NOAA) award no. NA21NOS4190021, and by Institutional Grant no. NA14OAR4170102 to the Texas Sea Grant College Program from the National Sea Grant Office, NOAA. All views, opinions, findings, conclusions, and recommendations expressed in this paper are those of the author(s) and do not necessarily reflect the opinions of the NOAA, Texas Sea Grant College Program or any subagencies of NOAA. Additional funding was provided by the Coastal Bend Bays \& Estuaries Program.

Conflict of Interest. KDS, TAP, MSW and JBP declare none.

Supplementary Materials. To view supplementary material for this article, please visit http://dx.doi.org/10.1017/exp.2020.44.

\section{References}

Bricker, S., Longstaff, B., Dennison, W., Jones, A., Boicourt, K., Wicks, C., \& Woerner, J. (2007). Effects of nutrient enrichment in the nation's estuaries: a decade of change. In NOAA coastal ocean program decision analysis series (Vol. 26, p. 328). National Centers for Coastal Ocean Science.

Bugica, K., Sterba-Boatwright, B., \& Wetz, M. S. (2020). Water quality trends in Texas estuaries. Marine Pollution Bulletin, 152, 110903. https://doi.org/10.1016/j.marpolbul.2020.110903.

Clark, J. F., Simpson, J. S., Bopp, R. F., \& Deck, B. (1992). Geochemistry and loading history of phosphate and silicate in the Hudson estuary. Estuarine, Coastal and Shelf Science, 34, 213-233.

Clarke, K. R., \& Ainsworth, M. (1993). A method of linking multivariate community structure to environmental variables. Marine Ecology Progress Series, 92, 205-219. https://doi.org/10.3354/meps092205.

de Santiago, K.Palmer, T., \& Beseres Pollack, J. (2020). Benthic macrofauna and water quality of Oso Bay Texas, $2013-2014$. Distributed by: Gulf of Mexico Research Initiative Information and Data Cooperative (GRIIDC), Harte Research Institute, Texas A\&M University-Corpus Christi, TX. https://doi.org/10.7266/D3PCKJSF

McLusky, D. S., Teare, M., \& Phizacklea, P. (1980). Effects of domestic and industrial pollution on distribution and abundance of aquatic oligochaetes in the Forth estuary. Helgoländer Meeresuntersuchungen, 33, 384-392. https://doi.org/10.1007/ BF02414763.

Pearson, T. H., \& Rosenberg, R. (1978). Macrobenthic succession in relation to organic enrichment and pollution of the marine environment. Oceanography and Marine Biology: An Annual Review, 16, 229-311.

Pinckney, J. L., Paerl, H. W., Tester, P., \& Richardson, T. L. (2001). The role of nutrient loading and eutrophication in estuarine ecology. Environmental Health Perspectives, 109, 699-706.

Rosenfeld, A., \& Ortal, R. (1983). Ostracodes as indicators of water pollution in Nahal Harod, Northern Israel. In R. F. Maddocks (Ed.), Applications of ostracoda (pp. 229-237). University of Houston Geoscience.

Van Dokkum, H. P., Hulskotte, J. H. J., Kramer, K. J. M., \& Wilmot, J. (2004). Emission, fate and effects of soluble silicates (waterglass) in the aquatic environment. Environmental Science \& Technology, 38, 515-521.

Wang, H., Hu, X., Wetz, M. S., \& Hayes, K. C. (2018). Oxygen consumption and organic matter remineralization in two subtropical, eutrophic coastal embayments. Environmental Science \& Technology, 52, 13004-13014.

Wetz, M. S., Hayes, K. C., Fisher, K. V., Price, L., \& Sterba-Boatwright, B. (2016). Water quality dynamics in an urbanizing subtropical estuary (Oso Bay, Texas). Marine Pollution Bulletin, 104, 44-53. https://doi.org/10.1016/j. marpolbul.2016.02.013.

Cite this article: de Santiago K, Palmer TA, Wetz MS, Beseres Pollack J (2020). Response of macrobenthic communities to changes in water quality in a subtropical, microtidal estuary (Oso Bay, Texas) Experimental Results, 1, e34, 1-9. https://doi.org/ $10.1017 / \exp .2020 .44$ 


\title{
Peer Reviews
}

\section{Reviewing editor: Dr. Arne Linlokken}

Inland Norway University of Applied Sciences, Faculty of Applied Ecology, Agricultural Sciences and Biotechnology, Elverum, Norway, 2418

This article has been accepted because it is deemed to be scientifically sound, has the correct controls, has appropriate methodology and is statistically valid, and has been sent for additional statistical evaluation and met required revisions.

doi:10.1017/exp.2020.44.pr1

Review 1: Response of macrobenthic communities to changes in water quality in a subtropical, microtidal estuary (Oso Bay, Texas)

\author{
Reviewer: Dr. Chet F Rakocinski iD
}

University of Southern Mississippi Gulf Coast Research Laboratory, Coastal Sciences, Ocean Springs, Mississippi, United States, 39564

Date of review: 01 August 2020

\begin{abstract}
(C) The Author(s), 2020. Published by Cambridge University Press This is an Open Access article, distributed under the terms of the Creative Commons Attribution licence (http://creativecommons.org/licenses/by/4.0/), which permits unrestricted re-use, distribution, and reproduction in any medium, provided the original work is properly cited.
\end{abstract}

Conflict of interest statement. Reviewer declares none

Comments to the Author: This succinct article is well written with a clear take home message. It should prove interesting to other researchers and resource managers in the field of aquatic environmental science. Some suggestions for the authors to consider:

Abstract

- A connection should be made between the land cover and the stressors of concern

- what is the mechanistic connection between silicate as a proxy and other stressors shown to be correlated with silicate?

Introduction

-The role/connection of land cover is overlooked in the Introduction

Objective

-Connection between land cover and nutrients and other stressors is not made

-The temporal aspect of 'spatiotemporal' not addressed explicitly

Methods

-The temporal aspect of 'spatiotemporal' is not addressed explicitly, its only implied in the methods

- No details at all about the statistical analysis - at least should mention what was performed with Results which samples and in what context

- No reference to the temporal dimension while using the term, 'spatiotemporal', except as implied in the NMDS graph of multiple points per station - was there a temporal pattern?

-Oligochaetes are known to be indicators of organic enrichment in low salinities

-No explicit connection to land cover is made 
- Are correlations in table S3 adjusted for multiple testing error? (perhaps give threshold in legend); reviewer recognizes referring to $P$ values as 'statistically significant' is out of favor, but the problem of multiple testing as an influence on $\mathrm{P}$ values remains

Discussion

-Oligochaetes are known to be indicators of organic enrichment in low salinities

-Lack of referral to any connection with land cover

-No discussion of temporal dimension for a study that lasted one year

Conclusion

-Role and promise of silicate as an indicator?

-Land cover?

-Temporal dimension?

\section{Score Card}

Presentation

Is the article written in clear and proper English? (30\%)

Is the data presented in the most useful manner? (40\%)

Does the paper cite relevant and related articles appropriately? (30\%)

\section{Context}

4.5

Does the title suitably represent the article? (25\%)

Does the abstract correctly embody the content of the article? (25\%)

Does the introduction give appropriate context? (25\%)

Is the objective of the experiment clearly defined? (25\%)

Analysis

Are the limitations of the experiment as well as the contributions of the experiment clearly outlined? (20\%) 
Review 2: Response of macrobenthic communities to changes in water quality in a subtropical, microtidal estuary (Oso Bay, Texas)

\author{
Reviewer: Dr. Robert Dunn ${ }^{1,2}$ (D) \\ ${ }^{1}$ University of South Carolina, Georgetown, South Carolina, United States, $29440{ }^{2}$ North Inlet-Winyah Bay National Estuarine \\ Research Reserve
}

Date of review: 31 July 2020

(C) The Author(s), 2020. Published by Cambridge University Press This is an Open Access article, distributed under the terms of the Creative Commons Attribution licence (http://creativecommons.org/licenses/by/4.0/), which permits unrestricted re-use, distribution, and reproduction in any medium, provided the original work is properly cited.

Conflict of interest statement. Reviewer declares none.

Comments to the Author: This manuscript describes a set of benthic infauna samples and coincident water quality samples collected within Oso Bay, Texas, an impacted estuarine ecosystem with multiple point and non-point source discharge locations. The authors relate spatiotemporal changes in the community of benthic infauna with environmental parameters at 6 sites located across a gradient of water quality conditions.

I have just a few comments to improve the manuscript.

Introduction: Would be useful to describe why macrobenthos are particularly sensitive.

Objective: Clarify- a spatiotemporal gradient of [what type of] conditions? In addition, I suggest re-wording that the study focuses on spatial differences in benthic communities adjacent to regions which varied in land cover; differences in land cover themselves are not the focus of the manuscript.

Methods: A very brief description of the sampling methodology for benthic infauna would be useful. Could be as simple as "core samples"

Results: Overlaying the main community members on nMDS plot (Fig 2) would illustrate nicely why the communities at the saline sites differed from the 4 western sites.

Discussion: A sentence or two regarding the similarity of the upstream, hypersaline site and the site located at the inlet of Oso Bay would be a useful addition. E.g., does the inlet site reflect "natural" conditions, or is it also impacted? Given that the hypersaline discharge upstream acts as a source of salty water, is that leading to an artificial, pseudo-marine benthic community?

\title{
Score Card
}

Presentation

Is the data presented in the most useful manner? (40\%)

Does the paper cite relevant and related articles appropriately? (30\%)

Does the abstract correctly embody the content of the article? (25\%)

Does the introduction give appropriate context? (25\%)

Is the objective of the experiment clearly defined? (25\%) 
Are the limitations of the experiment as well as the contributions of the experiment clearly outlined? (20\%) 